Nevșehir Bilim ve Teknoloji Dergisi Cilt 6(ICOCEE 2017 Özel Sayı) 440-446 2017

DOI: 10.17100/nevbiltek.319890

URL: http://dx.doi.org/10.17100/nevbiltek.319890

\title{
Eskişehir'de Yer Alan Bazı Sulama Göletlerinin Su Kalitesinin Değerlendirilmesi
}

\author{
Arzu ÇiçEK ${ }^{1}$, Erhan UYSAL ${ }^{1}$, Esengül KÖSE ${ }^{2}$, Cem TOKATLI ${ }^{3, *}$ \\ ${ }^{1}$ Anadolu Üniversitesi, Mühendislik Fakültesi, Çevre Mühendisliği Bölümü, Eskişehir \\ ${ }^{2}$ Eskişehir Osmangazi Üniversitesi, Eskişehir Meslek Yüksekokulu, Eskişehir \\ ${ }^{3}$ Trakya Üniversitesi, İpsala Meslek Yüksekokulu, Edirne
}

$\ddot{O} z$

Bu çalışmada Eskişehir ilinde bulunan altı göletin (Keskin, Çukurhisar, Borabey Kanlıpınar, Sarısungur ve Yukarıkartal) yüzeysel su kaliteleri, bazı fizyokimyasal parametreler açısından (bulanıklık, nitrat, fosfat, fekal koliform, askıda katı madde, biyolojik oksijen ihtiyacı, sıcaklık, pH, oksijen saturasyonu ve çözünmüş oksijen) tespit edilmiştir. Yüzey suyu örnekleri, Eskişehir'deki 6 göletten mevsimsel olarak (2013 - 2014) toplanmıştır ve elde edilen veriler Su Kirliliği Kontrol Yönetmeliği'ne göre değerlendirilmiştir.

Anahtar Kelimeler: Eskişehir, Sulama göleti, Su kalitesi.

\section{Assessment of Water Quality in Some of Irrigation Ponds in Eskişehir}

Abstract

In this study, surface water quality of 6 ponds (Keskin, Çukurhisar, Borabey Kanlıpınar, Sarısungur and Yukarıkartal) located in Eskişehir were evaluated by determining some physiochemical parameters (turbidity, nitrate, phosphate, fecal coliform, suspended solids, biological oxygen demand, temperature, $\mathrm{pH}$, oxygen saturation and dissolved oxygen). The surface water samples were collected seasonally (2013 - 2014) from six ponds in Eskişehir and the detected data were evaluated according to the Water Pollution Control Regulations in Turkey.

Keywords: Eskişehir, Irrigation lake, Water quality.

"e-mail: tokatlicem@gmail.com 
1. Giriş

$\mathrm{Su}$, canlı varlıkların yaşamsal faaliyetlerini sürdürebilmeleri için önem taşıyan kaynakların başında yer almaktadır. Dünya'daki su kütlesi incelendiğinde, \% 69'u tuzlu su ve \% 2'si tatlı su olmak üzere toplamda \% 71'inin sularla kaplı olduğu görülmektedir [1]. 18. yüzyılın son çeyreğinde 1 milyar olan dünya nüfusu, 1950 yılında 2,5 milyar, 2013 sonunda ise yaklaşık 7 milyara ulaşmıştır. Dünya nüfusunun bu hızlı artı̧̧ı, sanayi ve teknolojinin aşırı gelişmesi ve çevre bilincinin yeteri kadar oluşmaması gibi nedenler dünyada su kaynaklarının giderek kirlenmesine ve azalmasına sebep olmaktadır [2 - 4]. Su kaynaklarının korunması için öncelikle mevcut su kalitesinin belirlenmesi ve kaynağın yararlı kullanımına karar verilmesi gerekmektedir. Su kaynaklarının kalitesi bir havzada kirlenme gerçekleştiğinde bunun en önemli göstergelerinden biridir [5, 6].

Bu çalışma kapsamında, Eskişehir İlinde bulunan göletlerden belirlenen 6 istasyondan 2013 2014 tarihlerinde mevsimsel olarak yüzeysel su örnekleri alınmıştır. Alınan örneklerde Bulanıklık, nitrat, fosfat, fekal koliform, askıda katı madde, biyolojik oksijen ihtiyacı, sıcaklık, $\mathrm{pH}$, oksijen saturasyonu ve çözünmüş oksijen analizleri yapılmıştır.

\section{Materyal ve Metot}

Çalışma alanı olarak Eskişehir İli çevresinde bulunan 6 adet gölet seçilmiş olup bunlar; Yukarıkartal, Sarısungur, Borabey, Çukurhisar, Keskin, Kanlıpınar göletleridir (Şekil 1). İstasyonlara ait koordinat bilgileri Tablo 1'de verilmiştir.

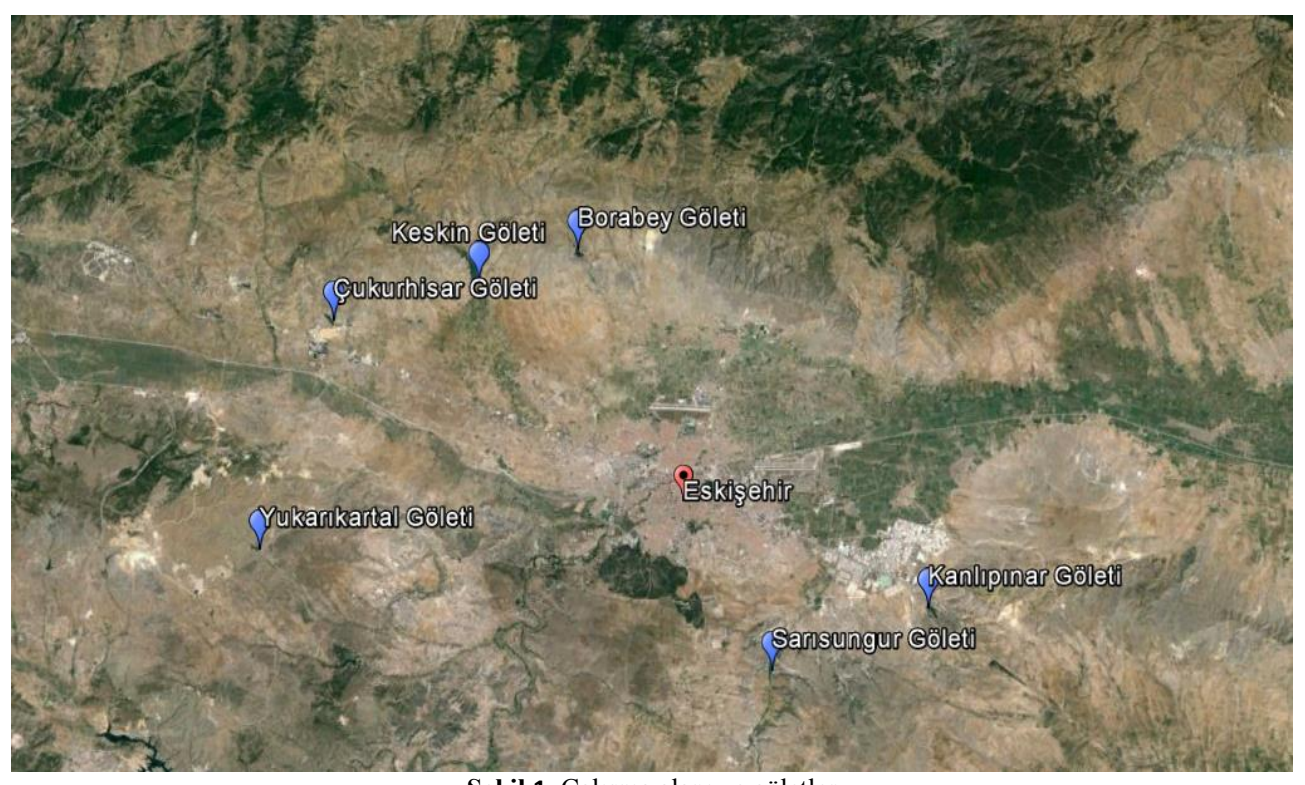

Şekil 1. Çalışma alanı ve göletler

Yukarıkartal göleti 144 hektarlık sulama alanına sahip, 1969-1971 yılları arasında yapılmış ve akarsuyu Kartal Deresi olan bir gölettir. Bu göletin depolama hacmi $0,540 \mathrm{hm}^{3}$, aktif hacmi $0,490 \mathrm{hm}^{3}$ ve ölü hacmi $0,050 \mathrm{hm}^{3}$ 'dür. Yukarkkartal göletinin talvegden yüksekliği 15,2 m ve temelden yüksekliği 18,7 m'dir [7]. 
Kanlıpınar göleti sulama amacıyla 1977-1978 yılları arasında yapılmıştır. Göletin akarsuyu Tıngır deresidir. Sulama alanı 120 hektardır. Depolama, aktif ve ölü hacmi sırasıyla $0,750 \mathrm{hm}^{3}, 0,700$ $\mathrm{hm}^{3}, 0,05 \mathrm{hm}^{3}$ 'dür. Göletin talvegden yüksekliği 17,2 m ve temelden yüksekliği 22,25 m'dir [7].

Çukurhisar göleti akarsuyu Ilgın deresidir ve bu gölet sulama amacıyla yapılmıştır. Gölet inşaatına 1986 yılında başlanmış ve tamamlanması 8 yıl sürerek 1994 yılında tamamlanmıştır. Göletin gövde dolgu tipi homojendir. Depolama hacmi $0,635 \mathrm{hm}^{3}$ ve aktif hacmi $0,585 \mathrm{hm}^{3}$ 'dir. Gölet sulama alanı 140 hektar olarak belirlenmiştir [7].

Keskin göleti sulama amacıyla yapılmış ve akarsuyu Karaöz deresidir. Baraj göletinin inşaası 8 yıl sürmüş ve 1998 yılında yapımı tamamlanmıştır. Göletin depolama, aktif ve ölü hacmi sırasıyla 8,400 $\mathrm{hm}^{3}, 7,760 \mathrm{hm}^{3}, 0,64 \mathrm{hm}^{3}$ 'dür. Keskin göleti gövde dolgu tipi homojendir ve sulama alanı 1112 hektardır [7].

Sarısungur göletinin temelden yüksekliği $36 \mathrm{~m}$ ve talvegden yüksekliği 24,5 m'dir. Göletin yapılış amacı sulama olup, sulama alanı 364 hektarlık bir alanı kapsamaktadır (DSİ). Göletin depolama hacmi 2600 hm 3’ dür. Gölet, rekreasyon amacının yanı sıra kullanma suyu ihtiyacını karşılaması, taşkın koruma, doğal hayatın korunması, sediment kontrolü, balıkçılık ve avcılık amaçları ile inşa edilmiştir [7].

Bir diğer adı da Emirceoğlu göleti olan Borabey göleti, Köy Hizmetleri İl Müdürlüğünce, 2480 dekarlık bir alana, 1991-1992 yılları arasında, 115 çiftçinin yararlanması amacıyla inşa edilmiştir ve sulama maksadıyla yapılmıştır [7].

Kasım 2013 - Ekim 2014 tarihleri arasında mevsimlik olarak yapılan arazi çalışmalarında, Eskişehir İlinde bulunan 6 göletten yüzeysel su örnekleri alınmıştır. Su örneklerinde bulanıklık, sıcaklık, pH, oksijen saturasyonu ve çözünmüş oksijen seviyeleri arazi çalışmaları sırasında Hach Lange marka multiparametre (HQ40D) su kalite ölçüm cihazı ve Hach Lange marka (2100Q) turbidimetre ölçüm cihazı ile; nitrat, fosfat ve biyolojik oksijen ihtiyacı değerleri, uygun koşullarda muhafaza edilerek laboratuvara getirilen örneklerde Hach Lange marka (DR 890) kolorimetre cihazı ile; fekal koliform değerleri ise En Muhtemel Sayı (EMS) analizi ile tespit edilmiştir (EN ISO 10304-1, EN ISO 10304-2, EN ISO 26777).

Tablo 1. İstasyonların koordinat bilgileri

\begin{tabular}{|c|c|c|c|}
\hline Gölet Adı & \multicolumn{2}{|c|}{ Koordinat } & Rakım (m) \\
\hline Keskin & $39^{\circ} 51^{\prime} 59.3^{\prime \prime}$ & $30^{\circ} 23^{\prime} 62.6^{\prime \prime}$ & 683 \\
\hline Borabey & $39^{\circ} 52^{\prime} 48.9^{\prime \prime}$ & $30^{\circ} 27^{\prime} 27.7^{\prime}$, & 464 \\
\hline Sarısungur & $39^{\circ} 41^{\prime} 35.5^{\prime \prime}$ & $30^{\circ} 34^{\prime} 24.6$ ', & 497 \\
\hline Çukurhisar & $39^{\circ} 50^{\prime} 56.7^{\prime \prime}$ & $30^{\circ} 18^{\prime} 37.7^{\prime \prime}$ & 230 \\
\hline Kanlıpınar & $39^{\circ} 43^{\prime} 14.7^{\prime \prime}$ & $30^{\circ} 40^{\prime} 03.4^{\prime \prime}$ & 241 \\
\hline Yukarıkartal & $39^{\circ} 44^{\prime} 50.8^{\prime}$, & $30^{\circ} 15^{\prime} 58.7^{\prime \prime}$ & 880 \\
\hline
\end{tabular}

\section{Bulgular}

Çalışmamız sonucunda elde edilen bulanıklık, nitrat, fosfat, fekal koliform, askıda katı madde, biyolojik oksijen ihtiyacı, sıcaklık, pH, oksijen saturasyonu ve çözünmüş oksijen verilerinin mevsimsel değişimi Şekil 2'de verilmiştir.

Su Kirliliği Kontrol Yönetmeliği'ne göre incelenen göletlerin genel olarak sıcaklık, BOİ, çözünmüş oksijen ve nitrat parametreleri açısından 1. sınıf su kalitesine sahip olduğu; fekal koliform parametresi açısından 3. sınıf su kalitesine sahip olduğu ve; $\mathrm{pH}$ parametresi açısından 3. - 4. sınıf su kalitesine sahip olduğu tespit edilmiştir [8]. 


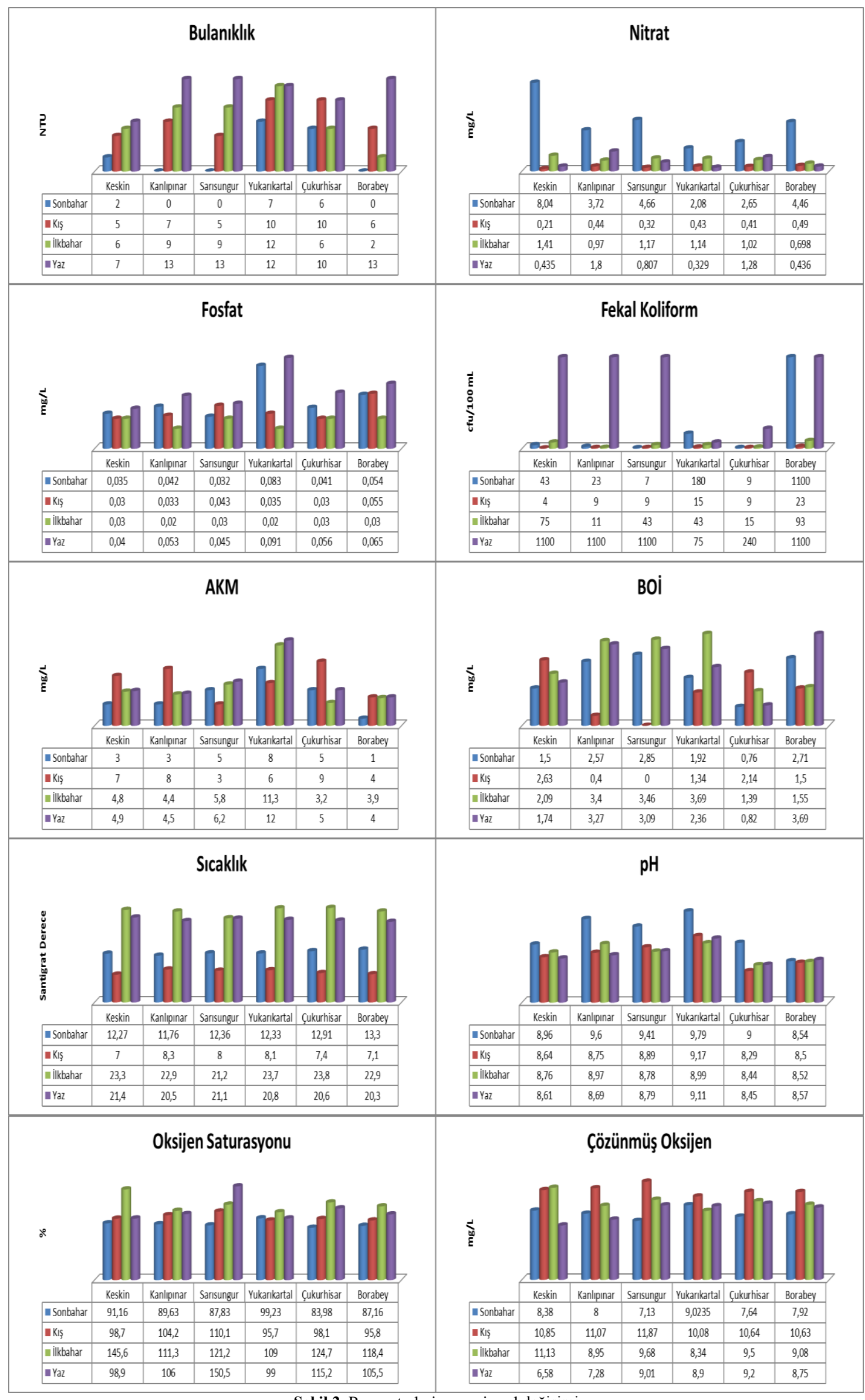

Şekil 2. Parametrelerin mevsimsel değişimi 


\section{Tartışma ve Sonuç}

pH, sularda kimyasal ve biyolojik açıdan önem taşımaktadır çünkü pH'nın artması yada azalması bazı bileşiklerin toksisitesini etkilemektedir [9, 10]. Zeybek [11], Akgöl'de bazı su kalitesi parametrelerini araştırmıştır. $\mathrm{Bu}$ parametrelerden biri olan $\mathrm{pH}$, çalışma süresince $8,4-8,9$ aralığında belirlenmiştir. Akgöl'ün, pH için verilen su kalite sınıflarının değerlerine göre incelendiğinde III. Sınıf su kalitesinde olduğu görülmüştür. Çalışmamız kapsamında ise alınan su örnekleri incelendiğinde, Keskin, Çukurhisar ve Borabey göletlerinin III. Sınıf su kalitesinde, Kanlıpınar, Sarısungur ve Yukarıkartal göletlerinin IV. Sınıf su kalitesinde olduğu belirlenmiştir [8]. Çalışmanın gerçekleştirildiği Sarısungur, Çukurhisar, Kanlıpınar ve Yukarıkartal Göletlerinin yakın çevrelerinde açık maden ocakları bulunmaktadır. $\mathrm{Bu}$ göletlerin $\mathrm{pH}$ parametresi açısından kalitesinin düşük olmasının çevrede bulunan maden ocakları ve bölgenin doğal formasyonundan kaynaklandığı düşünülmektedir.

Bulanıklık, su içerisinde bulunan süspansiyon maddeler sebebiyle oluşan opaklık derecesi olarak tanımlanmaktadır. Tüm doğal sularda değişik oranlarda süspansiyon madde bulunmaktadır ancak bu maddelerin miktarları farklı sebeplere bağlı olarak değişim göstermektedir [12]. Tokatlı [6, 13], Edirne Balkan Arboreum'unda yapmış olduğu çalışmalarda mevsimsel olarak bulanıklık değerlerini incelediğinde, yaz aylarında bulanıklık seviyesinin en yüksek olduğunu belirlemiştir. Çalışmamızda literatür bilgisine paralele olarak en yüksek bulanıklık değerleri yaz mevsiminde tespit edilmiştir.

Çözünmüş oksijen saturasyonunun derecesi suyun kirlenme derecesini ifade edebilmektedir. Ayrica bu saturasyon sudaki organik madde konsantrasyonu ve suyun kendi kendini ne derece temizleyebileceği hakkında da bilgi verebilmektedir [14]. Çalışmamızda incelenen tüm göletlerin çözünmüş oksijen saturasyonu açısından I. Sınıf su kalitesinde olduğu belirlenmiştir [8].

BOİ, organik maddenin parçalanması sırasında ihtiyaç duyulan oksijenin ifadesidir. Kirliliğin artmasıyla suda parçalanacak organik maddenin de oksijene ihtiyacı artmaktadır ve bu da BOİ değerinin yükselmesi anlamına gelmektedir [15]. Gürel [16], yaptığı çalışmada Ocak 2009 - Ekim 2009 tarihleri arasında mevsimsel olarak Porsuk Çayı su kalitesini belirlemeye çalışmıştır. Yapılan analizler sonucunda biyokimyasal oksijen ihtiyacı (BOİ) açısından Porsuk Çayı'nın IV. Sınıf su kalitesine sahip olduğu belirlenmiştir. Çalışmada tüm mevsimlerde ve tüm göletlerde BOİ seviyesinin $4 \mathrm{mg} / \mathrm{L}$ 'nin altında olduğu ve BOİ açısından tüm göllerin I. Sınıf su kalitesine sahip olduğu saptanmıştır [8].

Sularda nitrit ve nitrat kaynağı organik maddeler, azotlu gübreler ve doğadaki bazı mineraller olarak bilinmektedir. Nitrit sudaki oksijenle birleşerek nitrata dönüşür ve bu durum su kalitesi açısından oldukça önemlidir [17]. Çalışmamızda Keskin Göleti hariç (Keskin Göleti II. Sınıf) diğer göletlerin nitrat açısından I. Sınıf su kalitesine sahip olduğu belirlenmiştir [8].

Tokatlı ve ark. [10] yaptıkları çalışmada, Emet Çayı'nın fosfat değerlerinin genellikle yaz aylarında yüksek değerde ve sonbahar aylarında düşük değerlerde olduğunu tespit etmişlerdir. Çalışmada toplam fosfat seviyelerinin ilkbahar mevsiminde en düşük seviyede olduğu gözlenmiştir. Ötrofikasyon açısından en önemli bileşiklerden olan fosfatın, fitoplankton gelişiminin en yüksek seviyede olduğu ilkbahar mevsiminde düşük çıkması beklenen bir durumdur ve literatür bilgilerini destekler niteliktedir.

Uluslararası standartlarda kabul edildiği gibi; ülkemizde de toplam ve fekal koliform bakteriler su mikrobiyolojisi kalite standardı parametreleri olarak gösterilmektedir. Potansiyel patojen olan fekal koliform bakteri miktarının standartların üzerinde bulunması durumunda ise, suyun enfeksiyon yaydığ 1 
kabul edilmektedir [18]. Alkan ve ark. [19] yaptıkları çalışmada Uluabat Gölü'nün mikrobiyolojik kirlilik seviyesini belirlemeye çalı̧mıştır. Uluabat Gölü' nün kirlilik seviyesinin tespitinde gölün bazı noktalarının II. ve III. sınıf olduğu, fekal kirlenmenin yüksek olduğu bazı noktalarda ise IV. sınıf olduğunu gözlenmiştir. Çalışmamızda ise fekal koliform açısından tüm göletlerin III. Sınıf su kalitesinde olduğu belirlenmiştir [8].

\section{Teşekkür}

Bu çalışma, Erhan UYSAL'in "Eskişehir'deki Sulama Göletlenrinin Su Kalite İndekslerinin Belirlenmesi ve Ekolojik Açıdan Değerlendirilmesi" isimli yüksek lisans tezinden üretilmiştir.

\section{Kaynaklar}

[1] Tokatl1, C., "Drinking Water Quality Of a Rice Land in Turkey by a Statistical and GIS Perspective: İpsala District", Polish Journal of Environmental Studies, 23 (6): 2247-2258, 2014.

[2] Ödün, N. A., "Fırtına Vadis'nde (Çamlıhemşin-Rize) Çay Tarımında Kullanılan ve Doğal Gübrelerin Oluşturduğu Su Kirliliğinin Akuatik Ekosisteme Etkisi”, Yüksek Lisans Tezi, Recep Tayyip Erdoğan Üniversitesi, Fen Bilimleri Enstitüsü, 2013.

[3] Köse, E., Tokatlı, C., Çiçek, A., "Monitoring Stream Water Quality: A Statistical Evaluation", Polish Journal of Environmental Studies, 23 (5): 1637-1647, 2014.

[4] Tokatlı, C., Köse, E., Çiçek, A., "Assessment of the Effects of Large Borate Deposits on Surface Water Quality by Multi Statistical Approaches: A Case Study of the Seydisuyu Stream (Turkey)", Polish Journal of Environmental Studies, 23 (5): 1741-1751, 2014.

[5] Hepsağ, E., "Köyceğiz-Dalyan Lagün Havzası Su Kaynaklarının Su Kalitesi”, Yüksek Lisans Tezi, İstanbul Teknik Üniversitesi, Fen Bilimleri Enstitüsü, 2003.

[6] Tokatlı, C., "Water Quality Monitoring of Surface Resources in Balkan Arboretum Area (Trakya University, Edirne, Turkey)", Australian Journal of Basic and Applied Sciences, 11(5): 108112, 2017.

[7] Anonim, Eskişehir İli İşletmedeki Tesisler, DSİ III. Bölge Müdürlüğü, 2014. http://www2.dsi.gov.tr/bolge/dsi3/eski\%C5\%9Fehir.htm

[8] Yüzeysel Su Kalitesi Yönetimi Yönetmeliği (YSKYY), Orman ve Su İşleri Bakanlığı, Sayı: $28483,2012$.

[9] Tepe Y., Ateş A., Mutlu E., Töre Y. "Hasan Çayı (Erzin-Hatay) Su Kalitesi Özellikleri ve Aylık Değişimleri”, Ege Üniversitesi Su Ürünleri Dergisi, Cilt 23, Ek (1/1): 149-154, 2006.

[10] Tokatlı, C., Köse, E., Arslan, N., Emiroğlu, Ö., Çiçek, A., Dayığlu, H., "Water Quality of Emet Stream Basin”, Uludă University Journal of The Faculty of Engineering, 21 (2): 9-24, 2016.

[11] Zeybek, Z., "Akgöl'deki (Karaman-Konya) Bazı Su Kalitesi Parametrelerinin Araştırılması", Yüksek Lisans Tezi, Selçuk Üniversitesi, Fen Bilimleri Enstitüsü, Konya, 2006

[12] Bektaş S., Yıldırım A., Özvarol, Z. A. B., "Çoruh havzası farklı alabalık derelerinin bazı su kalite parametreleri yönünden karşılaş̧ırılması”, Biyoloji Bilimleri Araştırma Dergisi 4 (1): 6166, ISSN: 1308-3961, E-ISSN 1308-0261, 2011. 
[13] Tokatlı, C., "Use of Statıstıcal Methods in Water Quality Assesment: A Case Study of Balkan Arboretum Area in Trakya Unıversity (Edırne, Turkey)” Journal of Appiled Biological Sciences, 7 (3): 79-83, 2013.

[14] Ünlü A., Çoban F., Tunç M. S., "Hazar Gölü Su Kalitesinin Fiziksel ve İnorganik-Kimyasal Parametreler Açısından İncelenmesi”, Gazi Üniversitesi Mühendislik Mimarlık Fakülte Dergisi, Cilt 23, No 1, 119-127, 2008.

[15] Gökdemir Y., "Ergene Nehrindeki Ağir Metallerin Ekstraksiyon Metodu ile Tayini”, Yüksek Lisans Tezi, Trakya Üniversitesi Fen Bilimleri Enstitüsü, 2006.

[16] Gürel, E., "Porsuk Çayı Su Kalitesinin Belirlenmesi”, Yüksek Lisans Tezi, Eskişehir Osmangazi Üniversitesi, Fen Bilimleri Enstitüsü, 2011.

[17] Alaş A., Çil O., “Aksaray İline İçme Suyu Sağlayan Bazı Kaynaklarda Su Kalite Parametrelerinin İncelenmesi”, Çev-Kor, Cilt: 11 Sayı: 42, 40-44 2002.

[18] Akar, S., “İzmir iç Körfezi’nde, Kıyı Sularında ve Kara Midyelerde (Mytilus galloprovincialis Lamarck, 1819) Fekal Koliform Bakterilerin İzlenmesi”, Yüksek Lisans Tezi, Dokuz Eylül Üniversitesi, Fen Bilimleri Enstitüsü, İzmir, 2009.

[19] Alkan, U., Çalışkan, S., Mescioğlu, Ü., “Uluabat Gölü’nün Mikrobiyolojik Kirlilik Seviyesinin Belirlenmesi”, Ekoloji Çevre Dergisi, Sayı: 33, Ekim-Kasım-Aralık, 1999. 